\title{
BREVE HISTÓRICO A RESPEITO DO TRABALHO
}

\author{
Sergio Pinto Martins \\ Professor Associado de Direito do Trabalho da \\ Universidade de São Paulo
}

Resumo:

O estudo tem por objetivo apresentar os aspectos mais importantes do trabalho no curso do tempo e que acabam tendo influência no sistema brasileiro.

Abstract:

This study has for object to present the most important points of labour history, because they have influence in brazilian's system.

Unitermos: história do Direito do Trabalho.

\section{Introdução}

O Direito não deixa de ser uma realidade histórico-cultural, não admitindo o estudo de quaisquer de seus ramos sem que se tenha uma noção de seu desenvolvimento dinâmico no transcurso do tempo.

À luz da história podemos compreender com mais acuidade os problemas atuais. A concepção histórica mostra como foi o desenvolvimento de certa disciplina, além das projeções que podem ser alinhadas com base no que se fez no passado, inclusive no que diz respeito à compreensão dos problemas atuais. Não se pode, portanto, prescindir de seu exame. É impossível ter o exato conhecimento de um instituto jurídico sem se proceder a seu exame histórico, pois se verifica suas origens, sua evolução, os aspectos políticos ou econômicos que o influenciaram.

Ao analisar o que pode acontecer no futuro, é preciso estudar e compreender o passado, estudando o que ocorreu no curso do tempo, o progresso da tecnologia. Heráclito já dizia: o homem que volta a se banhar no mesmo rio, nem o rio é o mesmo rio e nem o homem é o mesmo homem. Isso ocorre porque o tempo passa e as coisas não são exatamente iguais como eram, mas precisam ser estudadas para se compreender o futuro. Para fazer um estudo sobre o que pode acontecer no 
futuro é necessário não perder de vista o passado. Não se pode romper com 0 passado, desprezando-o. Segundo as lições de Waldemar Ferreira, "nenhum jurista pode dispensar o contingente do passado a fim de bem compreender as instituições jurídicas dos dias atuais" ${ }^{1}$ No dizer de Antônio Álvares da Silva a história não termina, aperfeiçoa-se. ${ }^{2}$

É impossivel compreender o Direito do Trabalho sem conhecer o seu passado. Este ramo do Direito é muito dinâmico, mudando as condições de trabalho com muita freqüência, pois é intimamente relacionado com as questões econômicas.

II. Evolução histórica do trabalho em termos mundiais

Trabalho vem do latim "tripalium" que era uma espécie de instrumento de tortura ou uma canga que pesava sobre os animais.

Em inglês é utilizada a palavra "job" Essa palavra é antiga, remontando a período anterior ao ano de 1400 . Job" quer dizer hoje emprego. Pode ter sido uma variante de "gob" (bocado), um pedaço, naco, bocado. "Job" e "gob" podem ter origem numa palavra céltica "gob" ou "gop" que quer dizer boca. Inicialmente tinha a palavra significado de "pedacinho" de alguma coisa. Os ingleses que chegaram a Plymouth usavam a palavra com o significado de grande monte que seria transportado numa carroça. Posteriormente a palavra "job" passa a significar qualquer tarefa que fosse uma peça única de trabalho. Antes de 1800 a palavra 'emprego' se referia a alguma tarefa ou empreitada, porém não a um papel ou posição numa organização. Job" acrescido de um substantivo era usado para as pessoas contratadas para uma certa ocasião, como por exemplo: "job-coachman" (cocheiro), "job-doctor" (médico), etc. O verbo "to job" queria dizer fazer serviço avulso ou tarefa. ${ }^{3}$

Employment inicialmente tinha o significado de "aplicado a algum propósito específico" Hoje, tem sentido de emprego, ocupação, ofício, atividade,

1. Ferreira, Waldemar. História do Direito brasileiro, São Paulo, Ed. Saraiva, 1962, v. 1. p. 1.

2. Silva, Antōnio Álvares da. Co-gestão no estabelecimento e na empresa, São Paulo, LTr, pp. $112-3$.

3. Webster's New Universal Unabridged Dictionary, New York, Dorset \& Barber, 2a ed., 1983; The American Heritage Dictionary of the English Language, Boston. Houghton Mifflin Co, 1979; The Oxford English Dictionary, Oxford, The Clarendon Press, 1933. 
cargo. Out of employ seria o desempregado (unemployment). O verbo to employ quer dizer empregar, ocupar, utilizar.

Na Bíblia, o trabalho era uma espécie de pena, em razão dos pecados cometidos pelo homem. Dizia-se: "comerás o pão com o suor da tua fronte" 4

A primeira forma de trabalho a ser lembrada é a escravidão, em que 0 escravo era considerado apenas uma coisa, não tendo qualquer direito, muito menos trabalhista. O escravo, portanto, não era considerado sujeito de direito. Nesse período, constatamos que o trabalho do escravo continuava no tempo, até de modo indefinido, ou mais precisamente até o momento em que o escravo vivesse ou deixasse de ter essa condição. Entretanto, não tinha nenhum direito, apenas o de trabalhar.

Na Grécia, Platão e Aristóteles entendiam que o trabalho tinha sentido pejorativo. Envolvia apenas a força física. A dignidade do homem consistia em participar dos negócios da cidade por meio da palavra. Os escravos faziam o trabalho duro, enquanto os outros poderiam ser livres. $O$ trabalho não tinha 0 significado de realização pessoal. As necessidades da vida tinham características servis, sendo que os escravos é que deveriam desempenhá-las, ficando as atividades mais nobres destinadas às outras pessoas, como a política. Hesíodo, Protágoras e os sofistas mostram o valor social e religioso do trabalho, no sentido de que agradaria os deuses, criando riquezas e tornando os homens independentes. A ideologia do trabalho manual como atividade indigna do homem livre foi imposta pelos conquistadores dóricos (que pertenciam à aristocracia guerreira) aos aqueus. Nas classes mais pobres, na religião dos mistérios, o trabalho é considerado como atividade dignificante.

Num segundo momento, encontramos a servidão. Era a época do feudalismo, em que os senhores feudais davam proteção militar e política aos servos, que não eram livres, mas, ao contrário, tinham de prestar serviços na terra do senhor feudal. Deveriam os servos entregar parte da produção rural aos senhores feudais em troca da proteção que recebiam e do uso da terra. Evidenciava-se também a continuidade do trabalho até que o servo falecesse ou deixasse de ter essa condição. Inexistia, ainda, nesse momento contrato de trabalho.

Nessa época, o trabalho era considerado um castigo. Os nobres não trabalhavam. 
Na Inglaterra, em 1601, é editada a Lei de Amparo aos Pobres (Poor Relief $A c t)$, que tratava do direito dos pobres de receber auxílio das autoridades públicas.

Observamos num terceiro plano as corporações de ofício, em que existiam três personagens: os mestres, os companheiros e os aprendizes.

No início das corporações de ofício só existiam dois graus dentro dessas organizações: mestres e aprendizes. No século XIV. surge o grau intermediário dos companheiros.

Os mestres eram os proprietários das oficinas, que já tinham passado pela prova da obra-mestra. Os companheiros eram trabalhadores que percebiam salários dos mestres. Os aprendizes eram os menores que recebiam dos mestres o ensino metódico do ofício ou profissão. Verifica-se nessa fase histórica um pouco mais de liberdade do trabalhador, porém visavam-se aos interesses das corporações mais do que conferir qualquer proteção aos trabalhadores, inclusive quanto à continuidade do contrato de trabalho. As corporações de ofício tinham por objetivo: a) estabelecer uma estrutura hierárquica; b) regular a capacidade produtiva; c) regulamentar a técnica de produção. Os aprendizes trabalhavam a partir de 12 ou 14 anos, já se observando, em alguns países, a prestação de serviços com idade inferior. Ficavam os aprendizes sob a responsabilidade do mestre que, inclusive, poderia impor-lhes castigos corporais. Os pais dos aprendizes pagavam taxas, muitas vezes elevadas, para o mestre ensinar seus filhos. Se o aprendiz superasse as dificuldades dos ensinamentos era promovido ao grau de companheiro. O companheiro só passava a mestre se fosse aprovado em exame de obra-mestra, prova que era muito difícil, além de ter de pagar taxas para fazer o exame.

Nesse período, havia uma espécie de contrato de trabalho entre os companheiros e os mestres, porém inexistia garantia para a continuidade do referido pacto, simplesmente porque não havia uma garantia de o contrato perdurar no tempo. O mestre poderia terminar o pacto, sem que houvesse a necessidade de uma justificativa ou o pagamento de uma indenização.

A jornada de trabalho era muito longa, chegando até a dezoito horas no verão. Na maioria das vezes, terminava com o pôr-do-sol, por questão de qualidade de trabalho e não por proteção aos aprendizes e companheiros. A partir do momento em que foi inventado o lampião a gás, em 1792, por William Murdock, o trabalho era prestado em média entre doze e catorze horas por dia. Várias indústrias começaram a trabalhar no período noturno. 
As corporações de ofício foram suprimidas com a Revolução Francesa de 1789, pois foram consideradas incompatíveis com o ideal de liberdade do homem. Dizia Rousseau, na época, que a liberdade individual repele a existência de corpos intermediários entre o indivíduo e o Estado. ${ }^{5}$ Outras causas da extinção das corporações de ofício foram a liberdade de comércio e o encarecimento dos produtos das corporações.

Em 1791, logo após a Revolução Francesa, houve na França o início da liberdade contratual. O Decreto d'Allarde suprimiu de vez as corporações de ofício, permitindo a liberdade de trabalho. A Lei Le Chapelier, de 1791, proibia o restabelecimento das corporações de ofício, o agrupamento de profissionais e as coalizões, eliminando as corporações de cidadãos.

O liberalismo do século XVIII pregava um Estado alheio à área econômica, que, quando muito, seria árbitro nas disputas sociais, consubstanciado na frase clássica laissez faire, laisse passer, laissez aller.

A Revolução Industrial acabou transformando o trabalho em emprego. Os trabalhadores, de maneira geral, passaram a trabalhar por salários. Com a mudança, houve uma nova cultura a ser apreendida e uma antiga a ser desconsiderada.

Num primeiro momento, o contrato de trabalho era celebrado mediante livre acordo entre as partes. Entretanto, constatava-se que o empregador ainda era o senhor do trabalhador, extinguindo a relação a qualquer momento, sem qualquer responsabilidade. $O$ contrato era rescindido sem pagamento de indenização. Na prática, havia uma espécie de servidão, pois era explorado o trabalho dos menores e das mulheres, que, além de trabalharem jornadas excessivas de doze até dezesseis horas por dia, ainda tinham salários ínfimos.

Afirma-se que o Direito do Trabalho e o contrato de trabalho passaram a desenvolver-se com o surgimento da Revolução Industrial. Constata-se nessa época que a principal causa econômica do surgimento da Revolução Industrial foi o aparecimento da máquina a vapor como fonte energética. A máquina de fiar foi patenteada por John Watt, em 1738, sendo que o trabalho era feito de forma muito mais rápida com o referido equipamento. $\mathrm{O}$ tear mecânico foi inventado por Edmund Cartwright, em 1784. James Watt aperfeiçoou a máquina a vapor. A máquina de fiar de Hargreaves e os teares mecânicos de Cartwright também

5. Rousseau, Jean-Jacques. Du contrat social, Paris, Egloff, 1946, p. 73. 
acabaram substituindo a força humana pela máquina, terminando com vários postos de trabalho existentes e causando desemprego na época. Os ludistas ${ }^{6}$ organizavam-se para destruir as máquinas, pois entendiam que eram elas as causadoras da crise do trabalho. ${ }^{7}$ Com os novos métodos de produção, a agricultura também passou a empregar um número menor de pessoas, causando desemprego no campo. Inicia-se, assim, a substituição do trabalho manual pelo trabalho com o uso de máquinas. Havia necessidade de que as pessoas viessem também a operar as máquinas não só a vapor, mas as máquinas têxteis, o que fez surgir o trabalho assalariado. Daí nasce uma causa jurídica, pois os trabalhadores começaram a reunir-se, a associar-se, para reivindicar melhores condições de trabalho e de salários, diminuição das jornadas excessivas (os trabalhadores prestavam serviços por doze, catorze ou dezesseis horas diárias) e contra a exploração de menores e mulheres. Substituía-se o trabalho adulto pelo das mulheres e menores, que trabalhavam mais horas, percebendo salários inferiores. A partir desse momento, surge uma liberdade na contratação das condições de trabalho. O Estado, por sua vez, deixa de ser abstencionista, para se tornar intervencionista, interferindo nas relações de trabalho.

Com o surgimento da máquina a vapor, houve a instalação das indústrias onde existisse carvão, como ocorreu na Inglaterra. Bem retrata o trabalho abusivo a que eram submetidos os trabalhadores nas minas Emile Zola, em $O$ Germinal. O trabalhador prestava serviços em condições insalubres, estavam sujeitos a incêndios, explosões, intoxicação por gases, inundações, desmoronamentos, prestando serviços por baixos salários e trabalhando muito mais do que oito horas por dia. Ocorriam muitos acidentes de trabalho, além de várias doenças decorrentes dos gases, da poeira, principalmente a tuberculose e a asma. Trabalhavam direta ou indiretamente nas minas praticamente toda a família, o pai, a mulher, os filhos, os filhos dos filhos, etc. Os contratos de trabalho eram vitalícios ou então enquanto o trabalhador pudesse prestar serviços, implicando verdadeira servidão. Certos trabalhadores eram comprados e vendidos com seus filhos. Isso só terminou por meio dos decretos parlamentares de 1774 e 1779 , quando foram suprimidas essas questões nas minas escocesas.

$\mathrm{Na}$ Inglaterra, muitos menores trabalhavam por um prato de comida.

6. Trabalhadores ingleses seguidores de Nell Ludd.

7. Lefranc, Georges. Histoire du travail et des travailleurs, Paris, Flammarion, 1957, p. 245. 
Começa a haver necessidade de intervenção estatal nas relações de trabalho, dados os abusos que vinham sendo cometidos, de modo geral, pelos empregadores, a ponto de serem exigidos serviços em jornadas excessivas para menores e mulheres, de mais de dezesseis horas por dia ou até o pôr-do-sol, pagando metade ou menos dos salários que eram pagos aos homens.

No princípio, verificava-se que o patrão era o proprietário da máquina, detendo os meios de produção, tendo, assim, o poder de direção em relação ao trabalhador. Isso já mostrava a desigualdade a que estava submetido o trabalhador, pois este não possuía nada. Havia, portanto, necessidade de maior proteção ao trabalhador, que se inseria desigualmente nessa relação, inclusive quanto à cessação abrupta do contrato de trabalho pelo empregador.

Passa, portanto, a haver um intervencionismo do Estado, principalmente para realizar o bem-estar social e melhorar as condições de trabalho. O trabalhador passa a ser protegido juridicamente e economicamente. É como afirma Galart Folch: deve-se assegurar uma superioridade jurídica ao empregado em função da sua inferioridade econômica. A lei passa a estabelecer normas mínimas sobre condições de trabalho, que devem ser respeitadas pelo empregador.

A Lei de Peel, de 1802, na Inglaterra pretendeu dar amparo aos trabalhadores, disciplinando o trabalho dos aprendizes paroquianos nos moinhos $\mathrm{e}$ que eram entregues aos donos das fábricas. A jornada de trabalho foi limitada em doze horas, excluindo-se os intervalos para refeição. $O$ trabalho não poderia se iniciar antes das seis horas e terminar após às 21 horas. Deveriam ser observadas normas relativas à educação e higiene. Em 1819, foi aprovada lei tornando ilegal o emprego de menores de 9 anos. $O$ horário de trabalho dos menores de 16 anos era de doze horas diárias, nas prensas de algodão.

Na França, em 1813, foi proibido o trabalho dos menores em minas. Em 1814 foi vedado o trabalho aos domingos e feriados. Em 1839 foi proibido o trabalho de menores de 9 anos e a jornada de trabalho passa a ser de dez horas para os menores de 16 anos.

Karl Marx já dizia, por volta de 1867, quando publicou o primeiro volume de $O$ Capital, que a maior automação da produção acabaria por eliminar completamente o trabalhador. Marx declara que as mudanças tecnológicas transformam as operações do trabalhador cada vez mais em operações mecanizadas, até que, em determinado ponto, o mecanismo pode tomar o seu lugar. Assim, podemos ver diretamente como uma determinada forma de trabalho é 
transferida do trabalhador para o capital, na forma de máquina, e seu poder de trabalho, desvalorizado como resultado dessa transposição. Portanto, temos a luta do trabalhador contra a máquina. O que costumava ser atividade do trabalhador, passa a ser atividade da máquina" ${ }^{8}$ Entendia Marx que o desemprego era uma doença decorrente da acumulação do capital.

Adam Smith publica a Riqueza das Nações" em que considerava o trabalho humano a atividade aplicada à produção, sendo fonte de prosperidade.

A partir de 1880, passou a ser utilizada a eletricidade. Em consequiência, as condições de trabalho tiveram de ser adaptadas.

É interessante lembrar que, em seus primórdios, o Direito do Trabalho foi confundido com a política social. Estudavam-no cientistas sociais e outras pessoas que mais poderiam ser chamadas de revolucionários, tanto oriundos das faculdades, quanto dos parlamentos. Não havia diferença clara, até por falta de suficiente elaboração científica, entre os dois ramos do conhecimento. Os reformadores foram sendo pouco a pouco substituídos pelos juristas, voltados para 0 estudo da própria norma.

A história do Direito do Trabalho identifica-se com a história da subordinação, do trabalho subordinado. Verifica-se que a preocupação maior é com a proteção do hipossuficiente e com o emprego típico.

David Ricardo dizia, no início do século XIX, que as máquinas iriam destruir os empregos.

A Igreja também passa a preocupar-se com o trabalho subordinado. É a doutrina social. D. Rendu, Bispo de Annec, enviou um texto ao rei da Sardenha, em 15 de novembro de 1845, denominado "Memorial Sobre a Questão Operária" afirmando que "a legislação moderna nada fez pelo proletário. Na verdade, protege sua vida enquanto homem; mas o desconhece como trabalhador; nada faz por seu futuro, nem por sua alimentação, nem por seu progresso moral' ${ }^{9} \mathrm{O}$ trabalho dignifica pessoalmente o homem, merecendo valoração. Tem a doutrina social um sentido humanista.

A Encíclica "Rerum Novarum" (coisas novas), de 1891, do Papa Leão XIII, pontifica uma fase de transição para a Justiça social, traçando regras para a

8. Apud Mclellan, David. Marx's Grundrisse der Krilik der Politischen Ökonomie, New York, Harpers, 1977, p. 162.

9. Apud Costa, Orlando Teixcira da. O trabalho e a dignidade do trabalhador, in Revista LTr 59 . $05 / 592$. 
intervenção estatal na relação entre trabalhador e patrão. Já dizia o referido papa que não pode haver capital sem trabalho, nem trabalho sem capital" ${ }^{10}$ A Igreja continuou a preocupar-se com o tema, tanto que foram elaboradas novas encíclicas: "Quadragesimo Anno" de 1931, e Divini Redemptoris" de Pio XII; "Mater et Magistra" de 1961, de João XXIII; Populorum Progressio" de 1967. de Paulo VI; "Laborem Exercens" do Papa João Paulo II, de 14 de setembro de 1981.

Frederick Taylor estabelece uma forma de organização e racionalização do trabalho, por meio dos seus "Princípios de Administração Científica" (1895). Seriam quatro os princípios: 1. o estudo científico traria melhores métodos de trabalho; 2. seleção e treinamento científico da mão-de-obra; 3. estima e colaboração sincera entre a direção e a mão-de-obra; 4. distribuição uniforme do trabalho e das responsabilidades entre a administração e a mão-de-obra.

Henry Ford criou a linha de montagem na indústria automobilística, por meio da esteira móvel. Acabou incentivando aumentos de salários, para que seus empregados comprassem também os automóveis que fabricava. O fordismo seria a aplicação do taylorismo em grande escala. Tinha as seguintes características: adotava um sistema generalizante, não havendo especialista em determinada matéria; havia estratificação dos niveis hierárquicos na empresa; partia do pressuposto da auto-suficiência; pretendia atingir mercados nacionais e nãomercados globais, como temos hoje; envolvia o desenvolvimento de tecnologia de longa maturação, fazendo estoques de insumos e matérias-primas; existia um número muito grande de trabalhadores, com pagamento de baixos salários."

Ingressa-se numa nova fase denominada Constitucionalismo Social, em que as constituições dos países passam a ter regras sociais, principalmente de Direito do Trabalho.

A primeira Constituição que veio a incluir o Direito do Trabalho em seu bojo foi a do México, de 1917 O art. 123 da referida norma estabelecia jornada de oito horas de trabalho, proibição do trabalho de menores de 12 anos, limitação da jornada dos menores de 16 anos a seis horas, indenização de dispensa, seguro social, etc.

10. Lcão XIII, Encíclica Rerum Novarum, Capítulo 28.

11. Freitas Jr., Antonio Rodrigues de. Globalização, Mercosul e crise do Estado-Nação, São Paulo, LTr, 1997, pp. 65-66. 
A segunda Constituição a versar sobre o assunto foi a de Weimar, de 1919. Disciplinava a participação dos trabalhadores nas empresas, autorizando a liberdade de coalização dos trabalhadores. Criou não-só um sistema de seguros sociais, como também a possibilidade de os trabalhadores colaborarem com os empregadores na fixação de salários e demais condições de trabalho.

Surge o Tratado de Versalhes, de 1919, prevendo a criação da Organização Internacional do Trabalho (OIT), que iria incumbir-se de proteger as relações entre empregados e empregadores no âmbito internacional, expedindo convenções e recomendações nesse sentido.

Na Itália, é editada a Carta del Lavoro, de 1927. instituindo um sistema corporativista-fascista, que inspirou outros sistemas políticos, como os de Portugal, Espanha e, especialmente, do Brasil. O corporativismo visava organizar a economia em torno do Estado, promovendo o interesse nacional, além de impor regras a todas as pessoas. Surge o corporativismo na metade do século XIX com o fim de organizar os interesses divergentes da Revolução Industrial. O Estado interferia nas relações entre as pessoas com o objetivo de poder moderador e organizador da sociedade. Nada escapava à vigilância do Estado, nem a seu poder. $\mathrm{O}$ Estado regulava praticamente tudo, determinando o que seria melhor para um, organizando a produção nacional. O interesse nacional colocava-se acima dos interesses dos particulares. Mussolini dizia, na época: "Tudo no Estado, nada contra o Estado, nada fora do Estado" As diretrizes básicas do corporativismo eram: a. nacionalismo; b. necessidade de organização; c. pacificação social; d. harmonia entre o capital e o trabalho.

A Declaração Universal dos Direitos do Homem, de dezembro de 1948, prevê alguns direitos aos trabalhadores, como limitação razoável do trabalho, férias remuneradas periódicas, repouso e lazer, etc.

Eis os aspectos essenciais para se compreender a evolução do trabalho, que têm decisiva influência no Brasil, principalmente o corporativismo italiano, a partir de 1932 em diante.

São Paulo, fevereiro de 2000. 